\title{
Pandemic Sociology
}

\section{MARTYN PICKERSGILL}

THE UNIVERSITY OF EDINBURGH

\begin{abstract}
In 1990, the sociologist Phil Strong wrote about "epidemic psychology" as part of his research on the recent history of AIDS. Strong described vividly how epidemics of fear, of explanation and moralization, and of (proposed) action accompanied the epidemic of the AIDS virus per se. In this essay, I draw on these formulations to think through the current COVID-19 crisis, illustrating too a pandemic of inequality. In so doing, I provide a sketch of a pandemic sociology.
\end{abstract}

\section{Keywords}

COVID-19; SARS-CoV-2; pandemic; expertise; sociology of knowledge

How do we make sense of the COVID-19 pandemic? Of the viral, material, epistemic, and affective flows that circulate around the world, in trickles and tides and tributaries and waves? These questions are urgent, but they resist easy answers-even while it is profoundly tempting to give them. Swathes of scholars across disciplines have something to offer. Still, some anchors can be found for our unmoored states from the canons of our disciplines. Sociologist Phil Strong's 1990 paper, "Epidemic Psychology" provides one of these.

Strong was working in the late 1980s on the recent social history of AIDS, and his article provides a powerful account of some of the psychosocial disruptions that epidemics can bring and of the sociological processes underlying them. Re-reading "Epidemic Psychology" during the current pandemic is an eerie experience, and the paper feels uncannily prescient. Strong reflects on how, alongside the epidemic of the virus itself, there are epidemics of fear, of explanation and moralization, and of (proposed) action. All these are readily apparent today during the global

\footnotetext{
${ }^{1}$ Martyn Pickersgill, Email: dlkleinman@gmail.com

Copyright (C) 2020 (Martyn Pickersgill). Licensed under the Creative Commons Attribution Non-commercial No Derivatives (by-nc-nd). Available at estsjournal.org.
} 
surge of SARS-CoV-2, and attention to them provides initial entry points for a pandemic sociology.

For those of us currently experiencing a "lockdown," and whose encounters with the wider world are through the internet in general and social media in particular, fear is obvious. Fears of catching the virus and of passing it on to others, fears for the safety of older relatives and of one's children, fear that governments simply do not care about who lives and dies. For Strong, the epidemic of fear "is also an epidemic of suspicion." In the COVID-19 pandemic, this finds form in concerns that for many governments the state of the economy outweighs public health, and worries that many kinds of experts are being discounted by politicians-while the influence of those with no credible expertise at all is far too powerful. As with all anxieties, they are formed through the mixing together of realities and imaginaries, biographies and anticipation. Fears are also often well-grounded in lived experience, and inspired by the direct claims of leaders themselves. They are potent and seem set to endure.

A pandemic of explanation and moralization has been strikingly evident since before COVID-19 had a name. Commentators around the world have often explained the spread of the virus through a rhetoric of blame. The governments of China, the UK, and the US (to name but a few), the WHO, big business, incautious citizens-all these and more have been blamed for COVID-19. Traditional and social media is hardly short of people--including academics-who feel that they speak from a special place of moral and epistemic hygiene, where their analyses and interventions are unproblematically right and true. As Strong noted: "For anyone who already has a mission to change the world--or some part of it-an epidemic is a new opportunity for change and conversion." The COVID-19 pandemic has provided a new occasion for some politicians, for instance, to capitalize on collective distress to advance their mission. In doing so, they drive forward policy and commentary that will increase suffering for countless individuals and communities.

A pandemic of (in)action is also palpable. Evermore voices are shouting either for the tightening of government restrictions that protect the health of populations or for an end to the limits on social and economic life that social distancing requires. Questions circulate widely regarding, for instance, what exactly a "lockdown" should look like, when it should have been or should again be introduced, and when and how it should stop. These have come from "a thousand different converts" with "their own plan of action, their own strategy for containing and controlling the disease." In a number of countries governmental action has increasingly come to be less about containment and control and more about "release" and "freedom." Social and organizational action has too often meant "kickstarting" economies through the relaxation of 
precautions that are known to be saving lives. In the process, it seems all too likely that new kinds of action will be needed to halt the spread a revitalized pandemic.

While Strong's para-epidemics are powerful analytic devices, they also elide some of the socio-material corollaries of disease. In particular, with COVID-19 we are seeing a pandemic of inequality. Who is asked to work, and who stays at home? Who is safe in their residence, and who is trapped there? Who even has a home? Who is cared about and who cares for? Who reaps financial reward, and who is impoverished? Who lives and who dies? Entrenched structural inequalities pattern morbidity and mortality, distress and death. Inequalities are also augmented through the pandemic: the experience of COVID-19 is not only worse for populations who are structurally disadvantaged, but those disadvantages are widened. The short- and long-term ramifications of this for societies, families, and individuals are profound. As Benjamin Crump said at the funeral of George Floyd-a Black man murdered by a White police officer in the USA--the "other pandemic" is "racism and discrimination." Systemic and interpersonal racism, sexism, heterosexism, cisgenderism, and sanism kill. With COVID-19, we can also see how the violence of discrimination extends and multiplies inequalities and the horrors that accompany them.

Traversing the landscape of coronavirus-related discourse is emotionally and intellectually demanding. Contributing meaningfully to it feels almost impossible when many have said so much and the suffering is so significant. It already seems a cliché to talk about what SARS-CoV-2 has exposed, in terms of the fragilities of infrastructures, bodies, economies, and communities. But we need to continue to talk about the deficiencies of systems, governments, and leaders. To indicate the discursive features of pandemic sociology is not to dismiss the legitimacy of fear, the necessity of explanation, the obligation of action, and the atrociousness of inequality. Far from it.

\section{Author Biography}

Martyn Pickersgill is Professor of the Sociology of Science and Medicine at The University of Edinburgh. He is also Co-Director of Research in the Usher Institute, Edinburgh Medical School, and Associate Director of the Wellcome Trust-supported Centre for Biomedicine, Self and Society. Martyn's work focusses on the social dimensions of biomedicine and mental health. 


\section{Acknowledgements}

I'm very grateful to Robert Dingwall for reminding me of the important work of Phil Strong, and to the ESTS peer reviewers, Daniel Lee Kleinman, and Katie Vann for their collegiate and incisive engagement with this essay. I acknowledge financial support from the following funders: ESRC [ES/S013873/1], MRC [MR/S035818/1] and Wellcome Trust [106612/Z/14/Z; 209519/Z/17/Z]. 